\title{
Propylthiouracil-induced Cryoglobulinemic Vasculitis
}

\author{
Abdullah Ozkok, Suheyla Kaya, Omer Celal Elcioglu and Ali Riza Odabas
}

Key words: propylthiouracil, cryoglobulinemia, vasculitis

(Intern Med 52: 2011-2012, 2013)

(DOI: 10.2169/internalmedicine.52.0739)

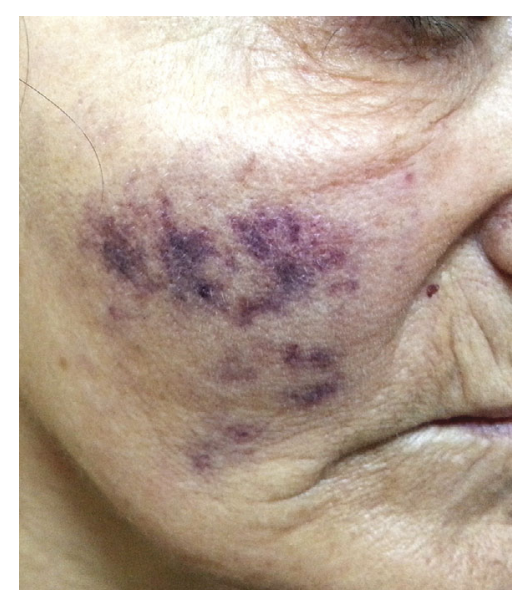

Picture 1.

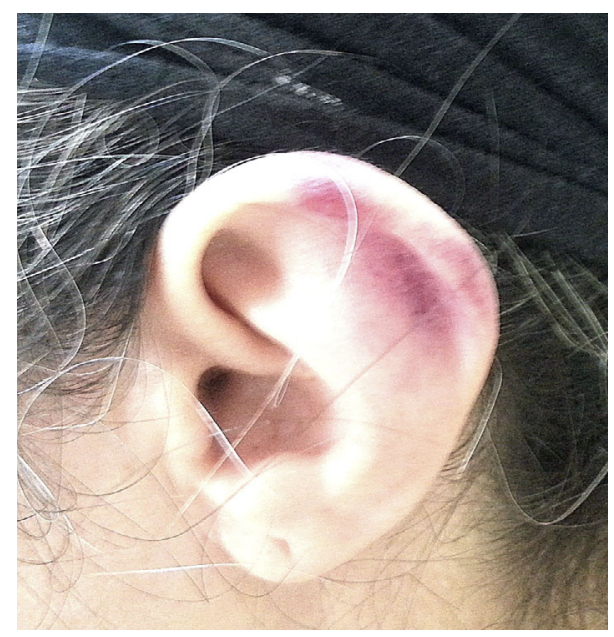

Picture 3.

A 56-year-old woman was admitted with purpuric lesions on the cheeks, lower legs and auricles (Picture 1-3). She had been treated for Graves' disease with propylthiouracil (PTU) for two years. The C-reactive protein level $(45 \mathrm{mg} / \mathrm{L})$ and erythrocyte sedimentation rate $(102 \mathrm{~mm} / \mathrm{h})$ were high. He-

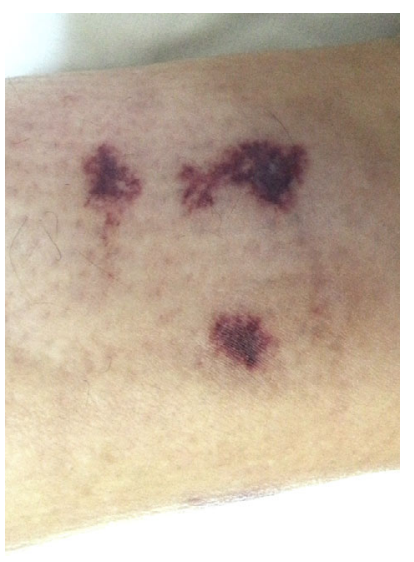

Picture 2.

maturia and non-nephrotic proteinuria (300 mg/day) were found. Anti-HCV and Anti-HBsAg were negative. The C3 level was normal $(83 \mathrm{mg} / \mathrm{dL})$; however, the $\mathrm{C} 4$ level was low $(7.15 \mathrm{mg} / \mathrm{dL})$. Antineutrophil cytoplasmic antibodies (pANCA) and myeloperoxidase-ANCA antibodies (MPOANCA) ( $>176 \mathrm{U} / \mathrm{mL}$ ) were positive. Cryoglobulin and cryofibrinogen tests were also positive. Under a diagnosis of PTU-induced cryoglobulinemic vasculitis, a skin biopsy was performed, which revealed leukocytoclastic vasculitis. The PTU was withdrawn and methimazole was started. The patient's skin lesions disappeared. The MPO-ANCA titer significantly decreased to $81 \mathrm{U} / \mathrm{mL}$, and cryoglobulins became negative.

PTU-induced ANCA-positive vasculitis has been well documented. However, PTU-induced cryoglobulinemia is extremely rare, having been reported in the literature only twice previously $(1,2)$. Since cryoglobulinemic vasculitis may present with life-threatening organ involvement, this disease should be kept in mind when encountering patients with PTU-induced vasculitis.

The authors state that they have no Conflict of Interest (COI). 
Intern Med 52: 2011-2012, 2013 DOI: 10.2169/internalmedicine.52.0739

\section{References}

1. Tu YL, Tsai YC, Huang JL, Yao TC. Occult pulmonary hemorrhage as a rare presentation of propylthiouracil-induced vasculitis. Pediatrics 127: e245-e249, 2011.
2. Zivanovic D, Dobrosavljevic D, Nikolic M, Bonaci-Nikolic B. Cryoglobulins and multispecific antineutrophil cytoplasmic antibodies in propylthiouracil-induced necrotizing cutaneous vasculitis: a new association. Eur J Dermatol 22: 707-709, 2012.

(C) 2013 The Japanese Society of Internal Medicine http://www.naika.or.jp/imonline/index.html 